\title{
Comparative in-vivo toxicity of venoms from South Asian hump-nosed pit vipers (Viperidae: Crotalinae: Hypnale)
}

Anjana Silva ${ }^{1 *}$, Panduka Gunawardena ${ }^{2}$, Danister Weilgama ${ }^{3}$, Kalana Maduwage ${ }^{4}$ and Indika Gawarammana ${ }^{5}$

\begin{abstract}
Background: Envenoming by south Asian hump-nosed pit vipers (Genus: Hypnale) is a significant health issue in Sri Lanka and in peninsular India. Bites by these snakes frequently lead to local envenoming, coagulopathy and acute renal failure even resulting in death. Recently the genus was revised and the existence of three species viz $H$. hypnale, H. nepa and H. zara were recognized. There is, however, a paucity of information on the toxicity of the venoms of these species. Hence, we compared the toxic effects of the three Hypnale venoms using BALB/c mice.

Findings: Intraperitoneal median lethal doses $\left(\mathrm{LD}_{50}\right)$ for $\mathrm{H}$. hypnale, $\mathrm{H}$. zara and $\mathrm{H}$. nepa venoms were 1.6, 6.0 and $9.5 \mathrm{\mu g}$ protein/g respectively. Minimum haemorrhagic doses for venoms of $H$. hypnale, $\mathrm{H}$. zara and $\mathrm{H}$. nepa were 3.4, 11.0 and $16.6 \mu \mathrm{g}$ protein/mouse respectively. The minimum necrotic doses for the same venoms were 15.0, 55.1 and $68.2 \mu \mathrm{g}$ protein/mouse respectively. Severe congestion and petecheal haemorrhages were observed in lungs, kidneys, liver and the alimentary tract. Histopathogical examination of kidneys revealed proximal tubular cell injury and acute tubular necrosis with intact basement membrane indicating possible direct nephrotoxicity. Hypnale venoms caused pulmonary oedema, hepatocellular degeneration and necrosis, focal neuronal degeneration in brain and extramedullary haemopoiesis in spleen. H. hypnale venom caused all above histopathological alterations at lower doses compared to the other two.
\end{abstract}

Conclusion: Hypnale venoms cause similar pathological changes with marked differences in the severity of the toxic effects in vivo. Therefore, differences in the severity of the clinical manifestations could possibly be seen among bite victims of the three Hypnale species.

Keywords: Hypnale, Nepa, Zara, Venom, Toxicity, Histopathology

\section{Findings}

\section{Background}

Hump-nosed pit vipers (genus: Hypnale) are a group of small sized pit vipers restricted to Sri Lanka and Western Ghats of South India. These snakes are the commonest cause of snake bite in Sri Lanka [1] and also lead to medically significant envenoming in Sri Lanka [2] and in India [3]. Systematics of the genus Hypnale was recently revised by Maduwage et al. [4] and three species namely, $H$. hypnale, $H$. nepa and H.zara were established. Each of the three species of Hypnale show unique geographical distribution and habitat characteristics [4].

\footnotetext{
* Correspondence: nkanjanasilva@gmail.com

${ }^{1}$ Department of Parasitology, Faculty of Medicine and Allied Sciences

Rajarata, University of Sri Lanka, Saliyapura, Sri Lanka

Full list of author information is available at the end of the article
}

Local envenoming is the commonest clinical effect among $H$. hypnale bite victims and could range from mild swelling to severe gangrene of bitten site [2]. Coagulopathy and renal failure have also been reported in many of $H$. hypnale victims $[2,5,6]$ and in one authenticated $H$. zara envenoming [7]. Clinical reports on $H$. nepa and $H$. zara bites, however, are extremely rare. Concerns on frequent potentially fatal envenoming caused by $H$. hypnale bites has been raised recently [2]. Although lethality, haemorrhagic and necrotic activity and several enzymatic activities of $H$. hypnale venom has been reported [8,9], such information is not available on the other two venoms. Recently, Maduwage et al. [10] showed the reverse phase high performance liquid chromatography profiles of the three Hypnale venoms to be similar. Further, they demonstrated similar

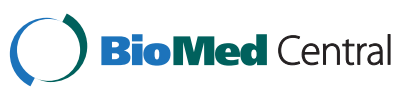


potent cytotoxic, weak procoagulant, neurotoxic, myotoxic and phospholipase $\mathrm{A}_{2}$ activities in all three Hypnale venoms. However, no clinical or basic in vivo experimental studies are available on the venom toxicity of $H$. nepa and H. zara.

The present study compares the Lethality $\left(\mathrm{LD}_{50}\right)$, haemorrhagic and necrotic activity of the three Hypnale venoms and describes Hypnale venom induced pathological changes in major organs of BALB/c mice.

\section{Materials and methods}

\section{Venom collection, preparation and storage}

The specimens of Hypnale species identified using keys described in Maduwage et al. [4] were used for venom collection.Venom was collected from the following: $H$. hypnale, 6 specimens from Galle $\left(06^{\circ} 03^{\prime} \mathrm{N}\right.$, $80^{\circ} 12^{\prime} \mathrm{E}$, elevation: $15 \mathrm{~m})$ and 2 specimens from Peradeniya $\left(07^{\circ} 15^{\prime} \mathrm{N}\right.$, $80^{\circ} 36^{\prime}$ E, elevation: $465 \mathrm{~m}$ ), H. nepa (4 specimens) from Agrapathana $\left(06^{\circ} 50^{\prime} \mathrm{N}, 80^{\circ} 40^{\prime} \mathrm{E}\right.$, elevation: $1665 \mathrm{~m}$ ) and H. zara (4 specimens) from Kottawa $\left(06^{\circ} 06^{\prime} \mathrm{N}, 80^{\circ} 20^{\prime} \mathrm{E}\right.$, elevation: $25 \mathrm{~m}$ ). The crude venom was desiccated using dehydrated silica gel in polyethylene containers. Venom crystals were dissolved in $0.9 \%$ sterile $\mathrm{NaCl}$ solution and $1 \%$ stock venom solutions prepared. For experiments, venoms were used within 6 months of the collection.

\section{Protein assay}

Since the pooled samples of the three Hypnale venoms were directly crystallized, quantification of venom proteins was performed in order to standardize the three venoms

Standardiztion was done using Bradford protein assay method [11]. BSA standard 0 to $2.0 \mathrm{mg} / \mathrm{ml}$ (Bio-Rad, USA) was prepared from dilution of a $2 \mathrm{mg} / \mathrm{ml}$ stock solution. Undiluted $300 \mu \mathrm{l}$ of Bradford Reagent (Sigma, Germany) was mixed with $10 \mu \mathrm{l}$ of venom sample in a microplate and allowed to develop for 5 minutes at room temperature before absorbance measurements at $595 \mathrm{~nm}$ in microplate reader (Molecular Devices, USA). A blank was prepared by using $10 \mu \mathrm{l}$ of sterile $0.9 \% \mathrm{NaCl}$ solution. All standards and samples were duplicated.

All doses of venom mentioned in this paper refer to respective venom protein doses expressed either as $\mu \mathrm{g} / \mathrm{g}$ or $\mu \mathrm{g} /$ mouse.

\section{Mice}

$\mathrm{BLAB} / \mathrm{c}$ mice of both sexes, 10-12 weeks old, weighing 18-23 g reared at Animal facility, Faculty of Medicine and Allied Sciences, Rajarata University, Sri Lanka were used. The animals were handled according to the guidelines given by CIOMS on animal experimentation [12]. Ethical clearance for the study was obtained from the Ethics Review Committee of the Faculty of Medicine and Allied Sciences, Rajarata University.

\section{Assessment of lethality}

In lethality studies, venoms were injected intraperitoneally with varying venom protein doses ranging from 0.1 to $11.5 \mu \mathrm{g} / \mathrm{g}$ of mouse in a total volume of $300 \mu \mathrm{l}$. Following initial dose adjustment studies, median lethal doses $\left(\mathrm{LD}_{50}\right)$ of the three Hypnale venoms were ascertained by using six venom doses with five mice per each dose of each venom. Number of mice that died within 48 hours of envenoming in each test group was recorded. A control group of eight mice were injected with a similar volume of the diluent. The $\mathrm{LD}_{50}$ values with respective $95 \%$ confidence intervals (CI) were calculated using probit analysis method as described by Finney [13] using SPSS software version 17.0. The minimum venom dose that killed all the animals of a test group was considered as the minimum lethal dose (MLD).

\section{Assessment of haemorrhagic activity}

Haemorrhagic activity of the venoms was estimated using the method followed by Tan et al. [8].Groups of mice (for each venom: 5 groups, 3 per group) were injected intra-dermally with three Hypnale venoms in varying amounts diluted in sterile $0.9 \% \mathrm{NaCl}$ solution. Each mouse received a standard venom volume of $40 \mu \mathrm{l}$ in to the shaved dorsal skins. Mice were kept under light diethyl ether anesthesia with access to water and food until they were sacrificed at 90 minutes of venom injection. The dorsal skins of mice were removed and the minimum and maximum diameter of the haemorrhagic lesion on the inner side of the skin was immediately measured to the nearest $0.1 \mathrm{~mm}$ using a dial venire caliper (KWB, Switzerland). The mean of the diameter readings of the haemorrhagic lesions were plotted against the corresponding venom protein dose injected to each group and trend-lines for each Hypnale venom was drawn. Venom protein dose corresponding to a diameter of $10 \mathrm{~mm}$ was considered as the minimum haemorrhagic dose (MHD) [8].

\section{Assessment of necrotic activity}

Necrotic activity of venoms was estimated using the method followed by Tan et al. [8]. Mice (3 per group) were injected with varying doses of Hypnale venoms as described for haemorrhagic activity tests and were sacrificed after 72 hours. The mean diameter of the necrotic lesion on the inner side of skin was measured as described for haemorrhagic activity tests. The mean of the diameter readings of the necrotic lesions were plotted against the corresponding venom dose and trend-lines for each Hypnale venom was drawn. Venom protein doses corresponding to a necrotic lesion with a diameter of $5 \mathrm{~mm}$ was considered as the minimum necrotic dose (MND). 


\section{Gross and histopathological studies}

Necropsies were performed on a total of 60 mice envenomed with venoms of the three Hypnale species (20 per each venom) during lethality studies. The selected mice were representative of full dose range tested in the lethality studies and had different survival times. In addition, three mice that survived envenoming with each of the Hypnale venom were euthanized after 7 days necropsied. Control mice groups (2 mice per group) were euthanized at 2 hours, 12 hours, 24 hours and 7 days following injection of $300 \mu \mathrm{l}$ doses of sterile $0.9 \%$ $\mathrm{NaCl}$ solution intra-peritoneally and necropsies performed. At necropsy, gross appearance of liver, kidneys, stomach, intestines, heart, lungs, brain and spleens were observed and whole specimens were fixed in $10 \%$ formol saline at least for 1 week. They were sectioned and histologically processed, embedded in paraffin, and 4-5 $\mu \mathrm{m}$ sections were made in rotary microtome. Sections were stained with Haematoxylin and Eosin. Stained sections were examined using light microscopy separately by PG and AS, without knowing the type and doses of venoms used. Micrographs were obtained using a digital photomicrographic unit, (CU318, Micrometrics, USA).

\section{Results}

\section{Lethality, haemorrhagic and necrotic activity of Hypnale} venoms

Median lethal doses $\left(\mathrm{LD}_{50}\right)$ with $95 \%$ confidence intervals, MLD, MHD and MND of the three Hypnale venoms are given in Table 1. All three Hypnale venoms showed varying degrees of haemorrhagic and necrotic activities. $H$. hypnale venom had lowest $\mathrm{LD}_{50}, \mathrm{MHD}$ and MND values of all three venoms, followed by $H$. zara and then $H$. nepa.

\section{Hypnale venom induced pathological changes in mouse organs}

Gross and histopathological changes were observed in all organs examined except the heart. Changes observed in kidney, liver, lung, brain, spleen and intestine were similar with all three Hypnale venoms. The minimum dose of each Hypnale venom that led to each histopathological change differed drastically (Table 2). No macroscopic or microscopic pathological alterations

Table 1 Lethality, hemorrhagic and necrotic activities of the three Hypnale venoms

\begin{tabular}{llll}
\hline & H. Hypnale & H. nepa & H. zara \\
\hline LD $_{\mathbf{5 0}}(\mathbf{C l})(\boldsymbol{\mu g} / \mathbf{g})$ & $1.6(1.5-1.8)$ & $9.5(8.6-10.3)$ & $6.0(4.3-7.0)$ \\
MLD $(\boldsymbol{\mu g} / \mathbf{g})$ & 2.0 & 11.4 & 8.7 \\
MHD $(\boldsymbol{\mu g} /$ mouse) & 3.4 & 16.6 & 11.0 \\
MND $(\boldsymbol{\mu g} /$ mouse) & 15.1 & 68.2 & 55.1 \\
\hline
\end{tabular}

were noted in any of the above organs of the control mice (Figures 1g, 1h, 2f, 2g, 2h and 3d).

\section{Kidney}

Macroscopically, congestion and petecheal haemorrhages in medulla were observed.

Microscopically, congestion of glomeruli (Figure 1a) and peritubular vasculature (Figure $1 \mathrm{~b}$ ), petecheal haemorrhages in renal medulla (Figure 1c),degenerative changes in tubular cells (Figure 1d), tubular dilatation and flattening of tubular cells with interrupted tubular brush border were observed in mice that died as early as 3 hours of envenoming. Renal tubular necrosis (Figure 1e) was evident by nuclear pyknosis and shedding of the tubular cells into lumen (Figure 1f) predominantly in the proximal tubular cells. Necrosed tubules had intact basement membranes and these were evenly distributed within cortices. Tubular necrosis was extensive in mice that died 18 to 72 hours of envenoming. Glomerular changes were mild and were mainly restricted to congestion, dilatation and presence of hyaline material in Bowman's capsule.

\section{Liver}

In macroscopy, oedema and congestion were commonly seen. Severe congestion with mottled appearance(Figure 2a) was seen in some mice. Microscopically, congestion of liver sinusoids (Figure 2b) and centrilobular vacuolar degeneration of hepatocytes (Figure 2c) was consistent at low doses. Peri-portal vacuolar degeneration of hepatocytes (Figure 2d) was present, less commonly. Few necrosed hepatocytes with random distribution (Figure 2e) were present in some sections. No haemorrhages were observed macroscopically or microscopically even at the highest venom doses tested.

\section{Lung}

Macroscopically, pulmonary congestion, gross haemorrhages and petecheal haemorrhages were evident. Pulmonary congestion, oedema (Figure 3a) and petecheal haemorrhages (Figure. 3b) were observed microscopically. The latter was observed, even at venom doses less than $\mathrm{LD}_{50}$ values. Inflammatory cell infiltrate predominately with lymphocytes and with few polymorphoneuclear cells in alveolar septae and peribronchial areas was observed (Figure. 3c).

\footnotetext{
Brain

Focal areas of neuronal degeneration (Figure. 3e) were seen in cerebral gray matter of mice envenomed with all Hypnale venoms.
} 
Table 2 Minimum doses of the three Hypnale venoms led to each observed histopathological alteration in BALB/c mouse organs

\begin{tabular}{lccc}
\hline \multicolumn{1}{c}{ Histopathological change } & \multicolumn{2}{c}{ Minimum venom dose $(\boldsymbol{\mu g} / \mathbf{g})$} \\
\cline { 2 - 4 } & H. hypnale & H. nepa & H. zara \\
\hline Petecheal haemorrhages in renal paranchyma & 0.9 & 4.8 & 3.2 \\
Degenerative changes in renal tubules & 0.4 & 8.9 & 2.2 \\
Renal tubular necrosis & 1.2 & 3.8 & 4.4 \\
Degeneration of hepatocytes & 0.5 & 5.2 & 2.1 \\
Random hepatocellular necrosis & 0.7 & 3.6 & 2.8 \\
Congestion in lung paranchyma & 0.3 & 5.1 \\
Haemorrhage into alveolar spaces & 1.3 & 4.8 \\
Inflammatory infiltrate in alveolar sepate & 1.3 & 7.6 \\
Pulmonary oedema & 1.6 & 3.7 \\
Focal neuronal degeneration in brain & 1.8 & 3.2 \\
\hline
\end{tabular}

\section{Spleen}

Spleens were highly congested, oedematous and friable in mice that died. However, in those that survived for 7 days, gross spleenomegaly was evident, at times being about double the normal size. In microscopy, petecheal haemorrhages were seen in red pulp of spleen in few of the mice following envenoming by $H$. hypnale venom. Presence of numerous small islands of darkly stained cells in red pulp of subcapsular area (Figure. 3f), presence of numerous aggregations of megakaryocytes (Figure. 3g) and large aggregates of haemosiderin engulfed macrophages were seen in spleens of mice, after 7 days post envenoming.

\section{Stomach, small and large intestine}

Severe congestion was noted macroscopically and microscopically, in stomach and in the small and large intestines of mice envenomed with all three Hypnale venoms.
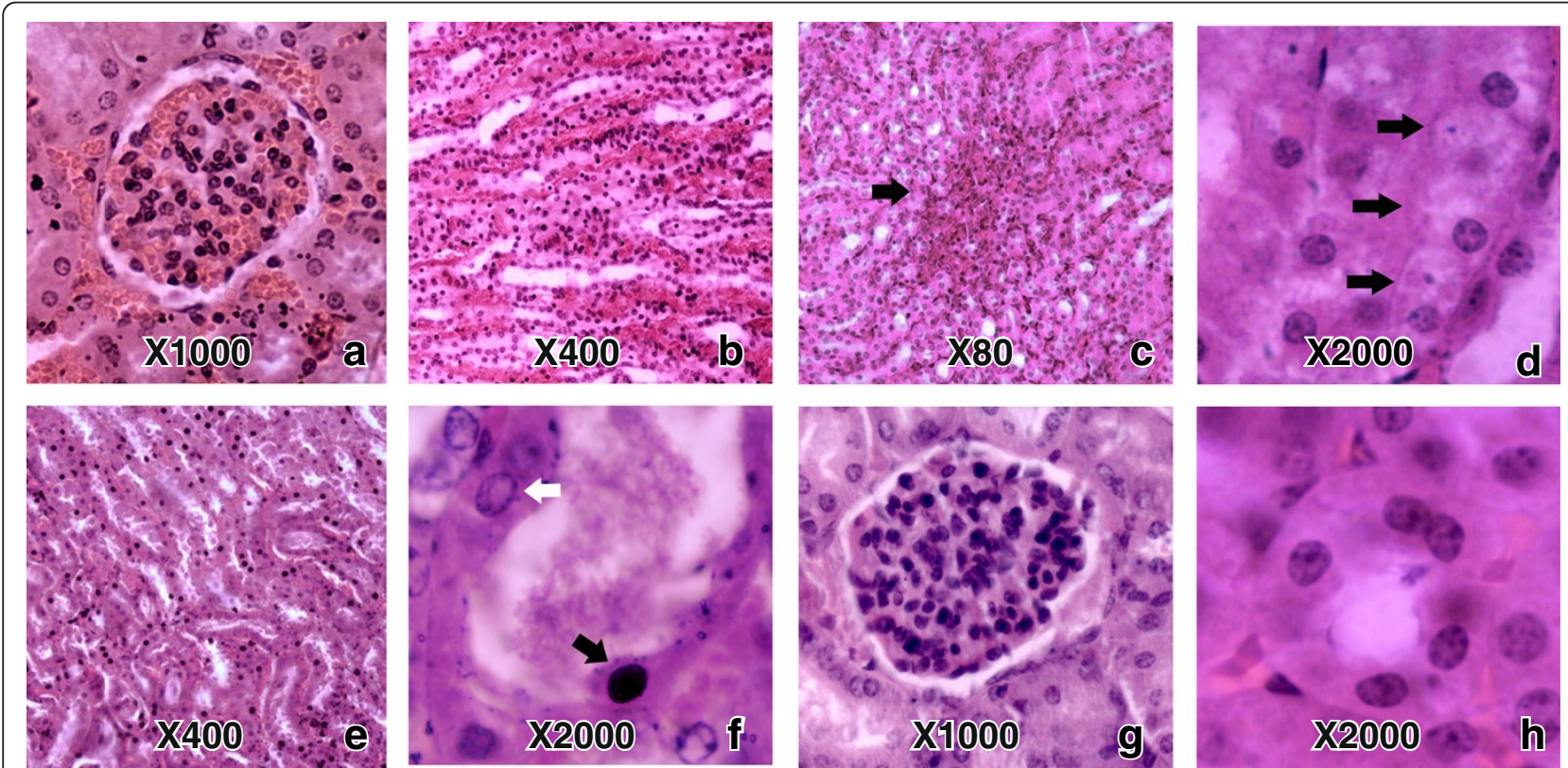

Figure 1 Histopathological changes caused by H. hypnale, H. nepa and H. zara venoms in mouse kidneys. (Note: the histopathological changes caused by the three Hypnale venoms were similar. The dose and the type of venom led to each histopathological change in representative photographs are mentioned within the parenthesis) Congested glomeruli (a: $2.3 \mu \mathrm{g} / \mathrm{g}$ dose of $\mathrm{H}$. hypnale venom) and peritubular vasculature (b: $2.3 \mathrm{\mu g} / \mathrm{g}$ dose of $\mathrm{H}$. hypnale venom); petechial haemorrhages in renal paranchyma(c: $2.5 \mu \mathrm{g} / \mathrm{g}$ dose of $\mathrm{H}$. hypnale venom); hydrophic degeneration of tubular cells (d: $7.0 \mu \mathrm{g} / \mathrm{g}$ dose of H. zara venom); tubular necrosis (e: $9.0 \mathrm{\mu g} / \mathrm{g}$ dose of H. zara venom)(note dilated tubules, many tubular cells with high cytoplasmic eosiophilia and pyknotic nuclei); dilated and necrosed proximal tubule (f: $9.0 \mathrm{\mu g} / \mathrm{g}$ dose of $\mathrm{H}$. zara venom) filled with hyaline material and having tubular cells with pyknosed nuclei (black arrow) and a vesicular nuclei (white arrow) as seen in test mice. Normal glomerulus (g: $0.9 \%$ sterile $\mathrm{NaCl}$ solution) and proximal tubule (h: $0.9 \%$ sterile $\mathrm{NaCl}$ solution) seen in control mice. 


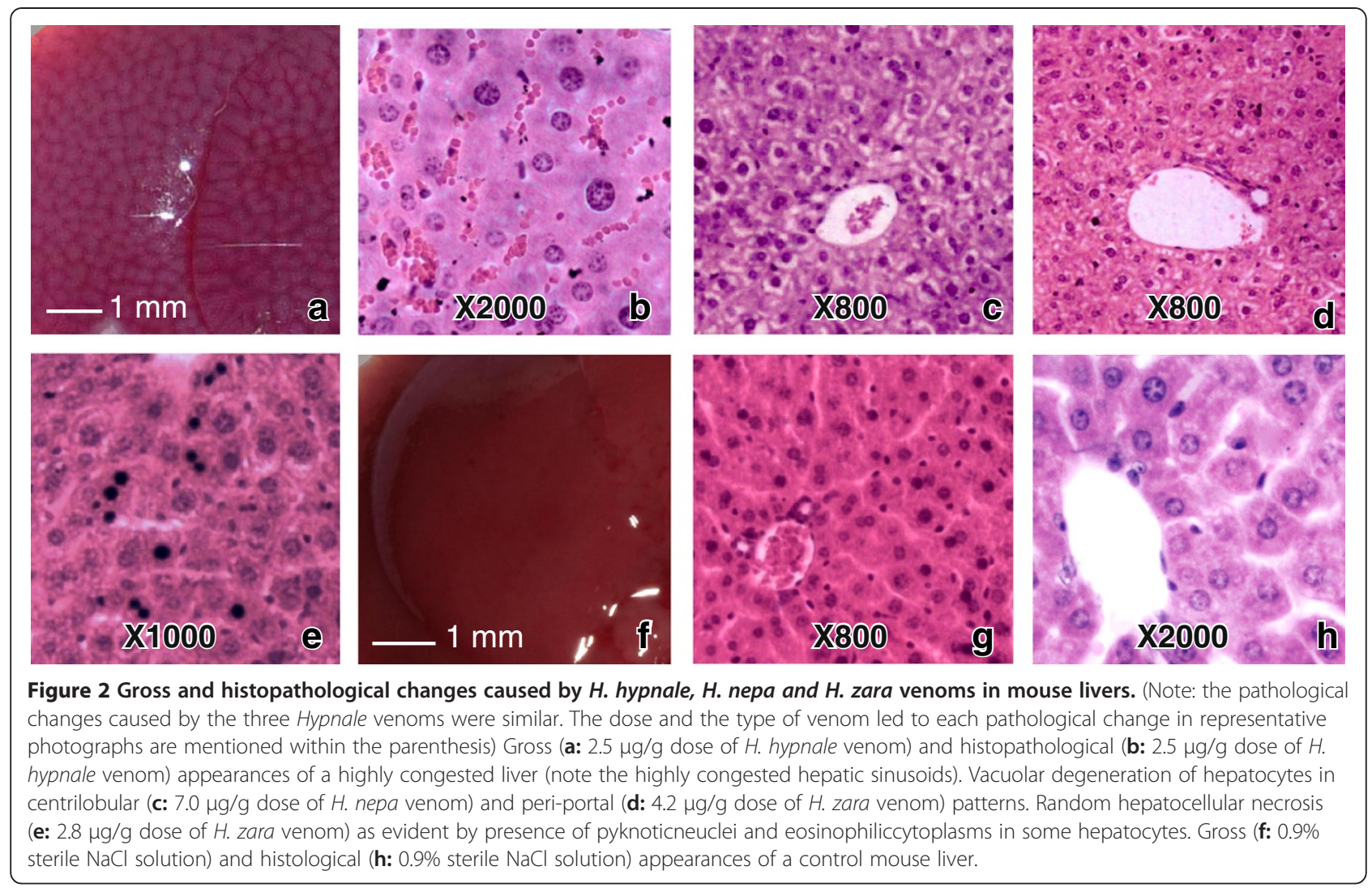

\section{Discussion}

The present study suggests that the in-vivo toxicity of the Hypnale venoms to be different among the three species. In comparison with other two venoms, markedly low $\mathrm{LD}_{50}$ value of $H$. hypnale venom suggests that the overall venom toxicity of this species is higher. Further, $H$. hypnale venom was found to be more haemorrhagic and necrotic, than the other two species. All three venoms however, had similar pathological effects on kidney, liver, lung, brain, spleen, stomach and intestines. Renal tubular necrosis with insignificant glomerular changes, degeneration of hepatocytes, pulmonary oedema and haemorrhage, patchy neuronal degeneration in cerebral grey matter and evidence of extramedullary haemopoiesis in spleen were the major histopathological findings in mice. The minimum venom doses that resulted in pathological alterations of mouse organs suggest that $H$. hypnale venom is more toxic to these organs than the other two venoms. This indicates a possible difference in the severity of envenoming among victims bitten by different Hypnale species.

Evenly distributed renal tubules with degeneration and necrosis, presence of intact basement membranes in severely necrosed tubules and absence of disarrayed tubular architecture suggest direct nephrotoxicity due to Hypnale venoms. Similar observations have been reported by Gunatilake et al. [14], using rabbit kidney slice model. With the results of this study, it could be suggested that venoms of all three Hypnale species are capable of causing direct tubular injury. Maduwage et al. [4] demonstrated the potent in-vitro cytotoxic effects of three Hypnale venoms. Various cytotoxic components in snake venom lead to direct tubular injury in kidney [15]. Thus, such properties may have contributed to direct tubular injury in envenomed mice.

Bilateral renal cortical necrosis has been observed in Hypnale victims previously $[4,16]$. In addition, evidence for presence of thrombotic microangiopathy in seven of eleven Hypnale bite victims with severe acute kidney injury was described recently [17]. Renal histology of these patients showed multiple glomerular capillary thrombi along with necrosis of glomeruli and tubular epithelial cells. Recently, the role of thrombotic microangiopathy in causing acute renal injury in most snake bites, predominately in viperid bites was emphasized [18]. However, none of the mouse kidneys examined in this study had evidence of the effects of thrombotic microangiopathy. In any case, the etiology and mechanisms of developing thrombotic microangiopathy in snake bite victims has yet to be unraveled [18].

Severe local necrosis is a well documented feature of $H$. hypnale bite victims [2,19]. However, since venoms of $H$. nepa and $H$. zara too showed necrotic activity in this study, local necrosis is likely to be associated with the bites caused 

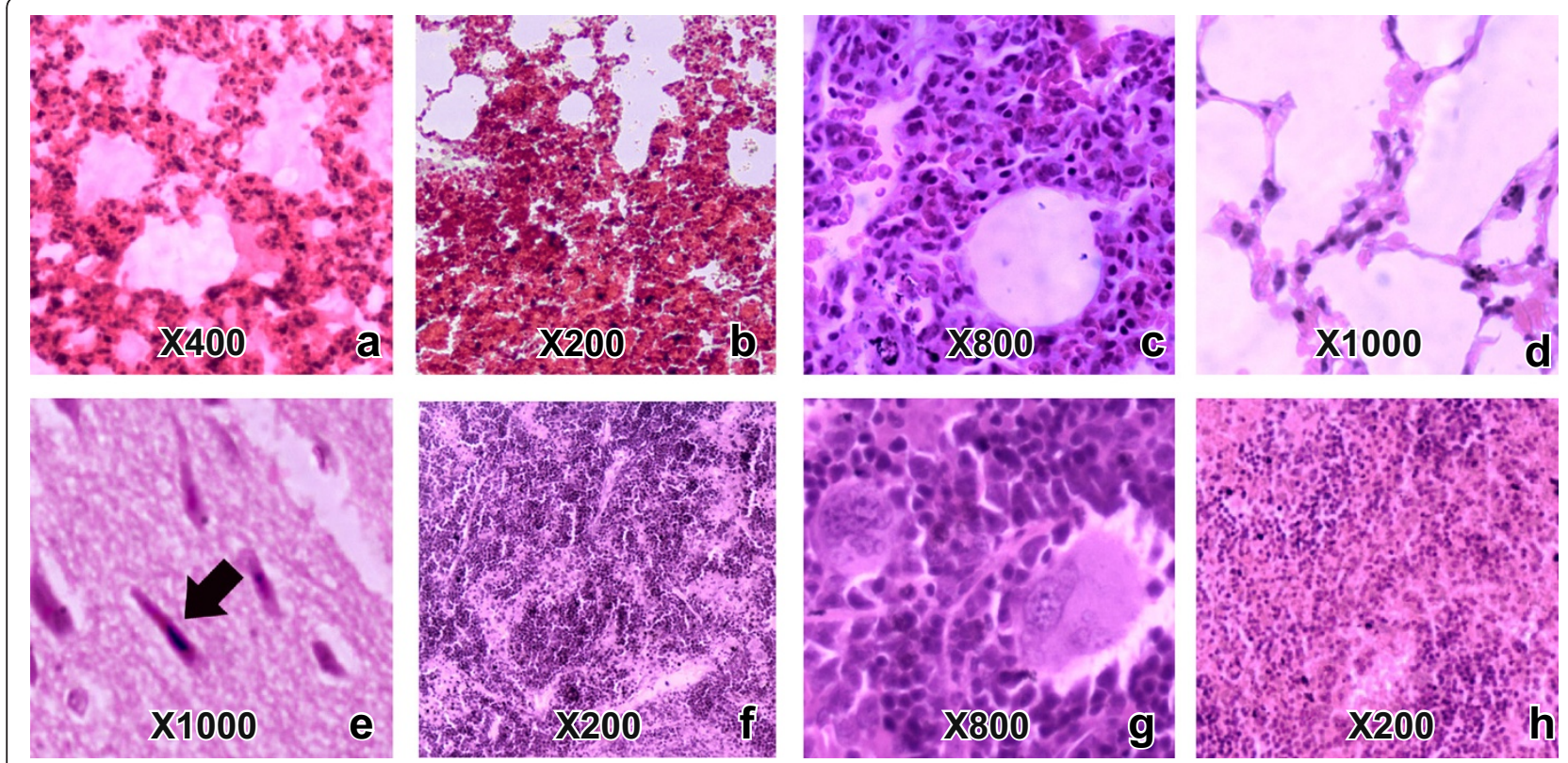

Figure 3 Histopathological changes caused by H. hypnale, H. nepa and H. zara venoms in mouse lungs, brains and spleens. (Note: the histopathological changes caused by the three Hypnale venoms were similar. The dose and the type of venom led to each histopathological change in representative photographs are mentioned within the parenthesis) Note severe pulmonary oedema (a: $2.3 \mu \mathrm{g} / \mathrm{g}$ dose of $\mathrm{H}$. hypnale venom), pulmonary interstitial haemorrhage (b: $3.0 \mu \mathrm{g} / \mathrm{g}$ dose of $\mathrm{H}$. hypnale venom), inflammatory cell infiltrate in alveolar septae (c: $1.4 \mathrm{\mu g} / \mathrm{g}$ dose of $\mathrm{H}$. hypnale venom) in lungs of test mice. Normal alveoli of a control mouse are shown in figure (d: $0.9 \%$ sterile $\mathrm{NaCl}$ solution). Ishchemic neuronal degeneration in cerebral cortex is shown in figure (e: $5.3 \mu \mathrm{g} / \mathrm{g}$ dose of $\mathrm{H}$. zara venom). Hyperplasia of the red pulp of spleen (f: $1.5 \mu \mathrm{g} / \mathrm{g}$ dose of $\mathrm{H}$. hypnale venom) as evident by large aggregations of immature stages of erythrocytes and presence of megakaryocytes $(\mathrm{g}: 6.0 \mathrm{\mu g} / \mathrm{g}$ dose of H. nepa venom) seen in splenic red pulp of test mice. Red pulp of a control mouse is shown in (h: $0.9 \%$ sterile NaCl solution).

by these two species. Potent cytotoxicity and Phospholipase $\mathrm{A}_{2}$ activity has been detected in all three Hypnale venoms [4], hence such prediction could be further justified.

Compared to the present study, intraperitoneal $L_{50}$, MHD and MND values for H. Hypnale reported by Tan et al. [8,9] were different and it is difficult to comment on this as the latter authors have not commented on the protein quantification.

Presence of haemorrhages in lungs and kidneys with doses below the respective $\mathrm{LD}_{50}$ values and absence of such in livers even with the highest respective venom doses tested might indicate organ specific haemorrhagic activity of Hypnale venoms. Pulmonary haemorrhage has not been observed in patients bitten by hump-nosed pit vipers as yet. It is known that metalloproteinases found in the snake venom are capable of inducing the release of inflammation mediators such as cytokines, intensifying the inflammatory response [20]. The occurrence of a large quantity of inflammatory cells in alveolar septae of mice may be due to such activity of the three venoms.

Degeneration and necrosis of hepatocytes observed in mice livers indicate hepatotoxicity in all three Hypnale venoms. Evidence for such activity has been observed in victims of $H$. hypnale bites $[16,21]$ and a victim of $H$. zara bite [7]. Barraviera et al. [22] hypothesized that hepatic injury as a frequent result of Crotaline envenomings.
Peri-portal area is the first area of the hepatic lobule to be exposed to a toxin being delivered through the bloodstream via the portal vein [23]. Compounds administered via intraperitoneal route are absorbed primarily through the portal circulation and, therefore, passes through the liver before reaching other organs [24]. Therefore, it could be surmised that peri-portal hepatocellular degeneration observed in mice are likely to be due to the effects of the venom absorbed via portal system.

Areas of neuronal degeneration in cerebral cortices of mice resembled ischemic neuronal degeneration. However, neither evidence of haemorrhage nor of thrombosis was revealed in these sections. Hence it is difficult to comment on the cause of these changes.

Presence of numerous small islands of darkly stained erythropoietic precursor cells seen in grossly enlarged spleens of mice, 7 days following envenoming, indicate extramedullary erythropoesis in spleen. Presence of numerous aggregations of megakaryocytes in red pulp also indicates production of platelets in spleen. Thrombocytopenia and anaemia have been observed in Hypnale victims previously [17]. The above observation indicates a response by spleen to such haemtological changes by hyperplasia and extramedullary haemopoesis.

Although the toxicity of the three Hypnale venoms were found to be clearly different as revealed in this 
study, these differences may not be much obvious in clinical situations. This is because the amount of venom injected during actual snake bite is subjected to large variations [25]. Several factors including size, sex, age of the snake also affect the toxicity of venom as well as the injecting venom volume in snake bite [25]. As clinical reports on $H$. nepa and $H$. zara envenomings are scarce [7] for the comparison, prospective clinical studies with accurately authenticated Hypnale bites would be helpful in correlating these findings to actual clinical situations.

\section{Conclusions}

There is a lacuna of information on species specific envenoming by hump-nosed pit vipers. In-vivo toxicity studies conducted on mice has shown that there is an appreciable variation in the toxicity of the venoms amongst the species of genus Hypnale. There is a need for detailed characterization of Hypnale venoms and the components. Future clinical reporting should appreciate species specific clinical effects of Hypnale envenoming.

\section{Abbreviations}

$\mathrm{LD}_{50}$ : Medial lethal dose; MHD: Minimum haemorrhagic dose; MLD: Minimum lethal dose; MND: Minimum necrotic dose.

\section{Competing interests}

The authors declare that they have no competing interests.

\section{Authors' contributions}

AS, DW, PG and IG designed the study, AS, DW and KM conducted experiments, AS and PG conducted histopathological studies, all authors participated in writing of the manuscript. All authors read and approved the final manuscript.

\section{Acknowledgements}

Prof. J. S. Edirisinghe (Rajarata University of Sri Lanka) is acknowledged for his generous help throughout the study. Ms. W. R. Jayaweera (University of Peradeniya) provided valuable assistance in histopathological studies. Messrs. P.K. Gamage, R.D.N. Pathirana, H.A.N.S. Hettiarachchi, J.M. Pushpakumara (Rajarata University of Sri Lanka) and Mr. Amal Wijesekara are acknowledged for technical assistance.

\section{Author details}

'Department of Parasitology, Faculty of Medicine and Allied Sciences Rajarata, University of Sri Lanka, Saliyapura, Sri Lanka. ${ }^{2}$ Department of Veterinary Pathobiology, Faculty of Veterinary Medicine and Animal Science, University of Peradeniya, Peradeniya, Sri Lanka. ${ }^{3}$ Department of Parasitology, Faculty of Medicine and Allied Sciences Rajarata, University of Sri Lanka, Saliyapura, Sri Lanka. ${ }^{4}$ School of Medicine and Public Health, University of Newcastle, NSW, Australia. ${ }^{5}$ Department of Medicine, Faculty of Medicine, University of Peradeniya, Peradeniya, Sri Lanka.

Received: 26 June 2012 Accepted: 27 August 2012

Published: 29 August 2012

\section{References}

1. Kasturiratne A, Pathmeswaran A, Fonseka MMD, Lalloo DG, Brooker S, de Silva HJ: Estimates of disease burden due to land-snake bite in Sri Lankan hospitals. Southeast Asian J Trop Med Public Health 2005, 36:733-740.

2. Ariyaratnam CA, Thuraisingam V, Kularatne SAM, Sheriff MHR, Theakston RDG, de Silva A, Warrell DA: Frequent and potentially fatal envenoming by hump-nosed pit vipers (Hypnale hypnale and H. nepa) in Sri Lanka: lack of effective antivenom. Trans R Soc Trop Med Hyg 2008, 102:1120-1126.

3. Joseph JK, Simpson ID, Menon NCS, Jose MP, Kulkarni KJ, Raghavendra GB, Warrell DA: First authenticated cases of life-threatening envenoming by the hump-nosed pit viper (Hypnale hypnale) in India. Trans R Soc Trop Med Hyg 2007, 101:85-90.

4. Maduwage K, Silva A, Manamendra-Arachchi K, Pethiyagoda R: A taxonomic revision of the South Asian pit viper genus Hypnale (Fitzinger). Zootaxa 2009, 2232:1-28.

5. Kularatne SA, Ratnatunga N: Severe systemic effects of Merrem's humpnosed viper bite. Ceylon Med J 1999, 44:169-170.

6. De Silva A, Wijekoon ASB, Jayasena L, Abeysekara CK, Bao CX, Hutton RA, Warrell DA: Haemostatic dysfunction and acute renal failure following envenoming by Merrem's hump-nosed viper (Hypnale hypnale) in Sri Lanka: first authenticated case. Trans R Soc Trop Med Hyg 1994, 88:209-212.

7. Maduwage K, Kularatne K, Wazil A, Gawarammana I: Coagulopthy, acute kidney injury and death following Hypnale zara envenoming - The first case report from Sri Lanka. Toxicon 2011, 58:641-643.

8. Tan CH, Leong PK, Fung SY, Sim SM, Ponnudurai G, Ariaratnam C, Khomvilai S, Sitprija V, Tan NH: Cross neutralization of Hypnale hypnale (hump-nosed pit viper) venom by polyvalent and monovalent Malayan pit viper antivenoms in vitro and in a rodent model. Acta Trop 2011, 117:119-124.

9. Tan CH, Sim SM, Gnanathasan CA, Fung SY, Ponnudurai G, Pailoor J, Tan NH: Enzymatic and toxinological activities of Hypnale hypnale (hump-nosed pit viper) venom and its fractionation by ion exchange high performance liquid chromatography. J Venom Anim Toxins 2011, 17:473-485.

10. Maduwage K, Hodgson WC, Konstantakopoulos N, O'Leary MA, Gawarammana I, Isbister GK: The in vitro toxicity of venoms from South Asian Hump-nosed pit vipers (Viperidae: Hypnale). J Venom Res 2011, 2:17-23.

11. Bradford $\mathrm{M}: \mathrm{A}$ rapid and sensitive method for the quantification of microgram quantities of protein utilizing the principle of protein-dye binding. Anal Biochem 1976, 72:248-254.

12. Howard-Jones NA: ACIOMS ethical code for animal experimentation. WHO Chron 1995, 39:51-56.

13. Finney DJ: Probit Analysis. England: Cambridge University Press; 1952.

14. Gunatilake M, Jayakody RL, Angunawala P, de Tissera A: Direct nephrotoxic effects produced by venoms of Sri Lankan cobra, Russell's viper and Hump-nosed viper. Ceylon J Med Sci 2003, 46:61-66.

15. Sitprija V: Snakebite nephropathy. Nephrology 2006, 11:442-448.

16. Varagunam T, Panabokke RG: Bilateral necrosis of the kidneys following snakebite. Postgrad Med J 1970, 46:449-451.

17. Herath N, Wazil A, Kularatne K, Ratnatunga N, Weerakoon K, Badurdeen S, Rajakrishna P, Nanayakkara N, Dharmagunawardane D: Thrombotic microangiopathy and acute kidney injury in hump-nosed viper (Hypnale species) envenoming: A descriptive study in Sri Lanka. Toxicon 2012, 60:61-65.

18. Isbister GK: Snakebite doesn't cause disseminated intravascular coagulation: coagulopathy and thrombotic microangiopathy in snake envenoming. Semin Thromb Hemost 2010, 36:444-451.

19. Sellahewa KH, Kumararatne MP: Envenomation by the Hump-nosed viper (Hypnale hypnale). Am J Trop Med Hyg 1994, 51:823-825.

20. Silveira KS, Boechem NT, Do Nascimento SM, Murakami YL, Barboza AP, Melo PA, Castro P, De Moraes VL: Pulmonary mechanics and lung histology in acute lung injury induced by Bothrops jararaca venom. Resp Physio Neurobiol 2004, 139:167-177.

21. Dharmaratne L, Gunawardena U: Generalized bleeding tendency and acute renal failure following Merrem's Hump-nosed viper bite. J Ceylon Coll Phy 1988-89, 21-22:37-42.

22. Barraviera B, Coelho KY, Curi PR, Meira DA: Liver dysfunction in patients bitten by Crotalus durissus terrificus snakes in Botucatu. Rev Inst Med Trop São Paulo 1995, 37:63-69.

23. Haschek WM, Rousseaux CG, Wallig MA: Fundamentals of Toxicologic Pathology. 2nd edition. London: Academic press; 2010.

24. Lukas G, Brindle SD, Greengard P: The route of absorption of intraperitoneally administered compounds. J Pharmacol Exp Ther 1971, 178:562-564.

25. Chippaux JP: Snake venoms and envenomations. Melbourne: Kreiger Publishing Company; 2006

doi:10.1186/1756-0500-5-471

Cite this article as: Silva et al:: Comparative in-vivo toxicity of venoms from South Asian hump-nosed pit vipers (Viperidae: Crotalinae: Hypnale). BMC Research Notes 2012 5:471. 